\title{
To Study The Prevalence of Ocular Manifestations in Rheumatoid Arthritis And their Correlation with Anti Cyclic Citrullinated Peptide Antibodies And Rheumatoid Factor .
}

\author{
Prempal Kaur ${ }^{1,}$ Bhavkaran Singh Bal ${ }^{2}$, Baljinderpal Singh ${ }^{3,}$ Ashok Duggal ${ }^{4,}$ \\ Inderjit Kaur \\ ${ }^{1}$ Associate Professor Ophthalmology. ${ }^{2}$ Junior Resident Orthopedics. ${ }^{3}$ Professor, Medicine. ${ }^{4}$ Associate \\ Professor,Medicine ${ }^{5}$ Professor Ophthalmology
}

\begin{abstract}
Introduction: Ocular involvement in rheumatoid arthritis $(R A)$ is significant as sometimes if missed can be potentially blinding.Their presence also aids in making the final diagnosis of RA with atypical presentation. During the course of treatment of RA, flaring of ocular signs and symptoms may signal impending deterioration or relapse of RA. Thus the study was undertaken in our tertiary care hospital to know the prevalence of ocular manifestations in patients of RA and their correlation with disease activity.

Material and Methods: The present prospective observational study was conducted in Regional Institute of ophthalmology on 139 patients of rheumatoid arthritis. Detailed ocular examination was done and besides routine investigations $R A$ factor $(R F)$ and anti cyclic citrullinated peptide antibodies $(A C C P)$ of each patient was recorded.Chi-square test was used to correlate their significance to ocular manifestations. Probability $(p)$ value less than 0.05 was considered significant.

Results: Among 139 patients of rheumatoid arthritis included in our study, 53(38\%) patients had ocular signs and symptoms. 31(22\%) patients had dry eye,13(9\%) had keratoconjunctivitis sicca(KCS), $7(5 \%)$ had anterior uveitis , 4(3\%) had episcleritis, 3(2\%) had scleritis, 2(1.4\%) had peripheral ulcerative keratitis(PUK), 2(1.4\%) had sclerosing keratitis, 5(3.5\%) had cataract,and1(0.7\%) had rental vasculitis. The prevalence of ocular manifestations was significantly higher in patients with positive serology than those with negative serology $(p<0.05)$.Patients with positive ACCP had higher rate of ocular complications that those with only RF positive but it was not statistically

significant. $(P>.05)$

Conclusion: Patients of rheumatoid arthritis need to get routine ocular examination for the early diagnosis and timely management so as to prevent permanent irreparable loss of vision. The presence of anti CCP antibodies and RF provides effective clue to ophthalmologists for identifying patients at risk for vision threatening inflammatory ocular complications.
\end{abstract}

Keywords: Rheumatoid arthritis,rheumatoid factor,ocular manifestations,Anti cyclic citrullinated peptide antibodies.

\section{Introduction}

Rheumatoid arthritis (RA) is a systemic inflammatory disease, which is associated with a number of extra-articular manifestations.Ocular involvement is very significant as it can be potentially blinding. It may range from the most common dry eye or keratoconjunctivitis sicca to site threatening keratitis, scleritis, anterior uveitis, vitritis, cataract formation or subluxation and rarely to more serious complications including retinal vasculitis and ischemic optic neuropathy or optic neuritis.[1-6] Even subtle signs of these coexisting ocular pathologies should not be overlooked. They may be the only clue in making the initial final diagnosis of RA in cases with atypical presentation and later on during the course of treatment flaring of ocular signs and symptoms may signal impending deterioration or relapse of RA. The diagnosis of RA depends upon symptoms,signs,radiographic findings and serological tests. Rheumatoid factor (RF) is positive in 70-80\% of RA patients and is associated with more aggressive joint disease and increased prevalence of extra ocular manifestations. However RF may be detected in other connective tissue diseases. [7] Antibodies to cyclic citrullinated peptide (CCP) can be detected by enzyme - linked immunosorbent assay (ELISA) and have been found to be more specific serum test for RA than RF. ACCP antibodies is 95\% specific for RA whereas RF is only $79 \%$ specific. ACCP antibodies are predictive of radiographic progression and other indicators of disease severity including extra ocular manifestations in patients of RA. Inversely while treating RA, like other extra articular presentations, ocular signs and symptoms should be kept in mind for timely management and consequent prevention of permanent loss of vision. Thus the study was undertaken in our tertiary care hospital to know the prevalence of ocular manifestations in patients of RA and their correlation with disease activity 


\section{Material And Methods}

The present prospective observational study was conducted in Regional Institute of ophthalmology on 139 patients of rheumatoid arthritis ,visiting Medicine and Orthopedic department of Government Medical College ,Amritsar between 1/1/15 and 31/12/15. After recording the demographic data of the patient,visual acuity was recorded, detailed anterior chamber examination was done on slit lamp to detect any evidence of dry eye syndrome (DES) ,episcleritis, scleritis,corneal changes or anterior uveitis. Presence of dry eye was confirmed after doing schirmer's test and tear film break up time. Fundus examination was done with $90 \mathrm{D}$ lens on slit lamp to detect any abnormality in the retina. Patients <16years of age, diabetics, with dry eyes ,uveitis,scleritis,glaucoma due to causes other than RA were excluded from the study. Patients with any other collagen disease were also excluded. Besides routine investigations and collagen profile, patient's RA factor(RF) and anti cyclic citrullinated peptide antibodies was recorded. The IgM RF was measured by nephelometry and was considered positive at $>40 \mathrm{IU} / \mathrm{mL}$. Anti-CCP antibody levels were detected using enzyme-linked immunosorbent assay (ELISA) and after 1:50 dilution was considered positive if it was $>5$ arbitrary units. Chi-square test was used to correlate their significance to ocularmanifestations. Probability (P) value less than 0.05 was considered significant.

\section{Observations}

One hundred and thirty nine diagnosed patients of rheumatoid arthritis (RA) referred from medicine and orthopedic department of Government Medical College to Regional Eye Institute between January 1,2015 and 31 December, 2015 were studied . 53( 38\%) of these patients had ocular signs and symptoms . Among them $81 \%$ were females and $19 \%$ were males (Fig 1). The mean age of the affected patients was $41.65 \pm 25.54$.

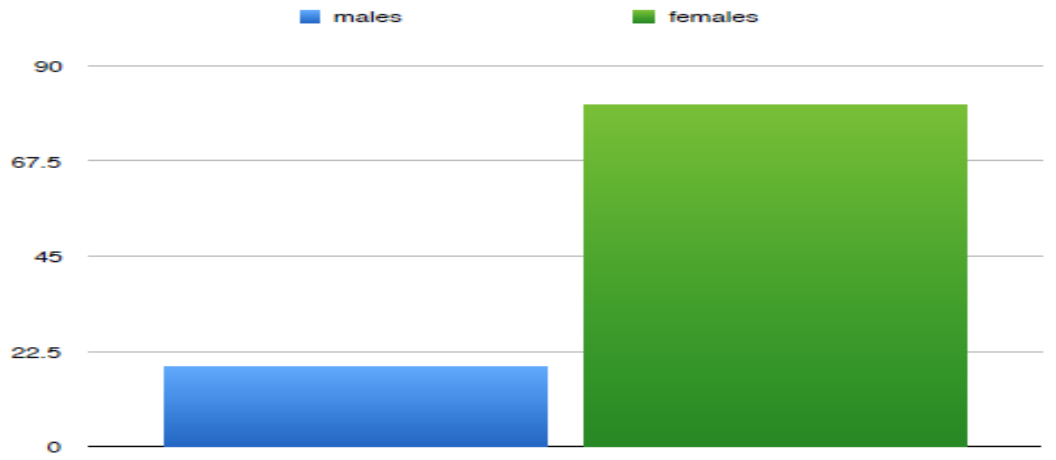

Fig.1 Sex distribution of patients with ocular manifestations with rheumatoid arthritis

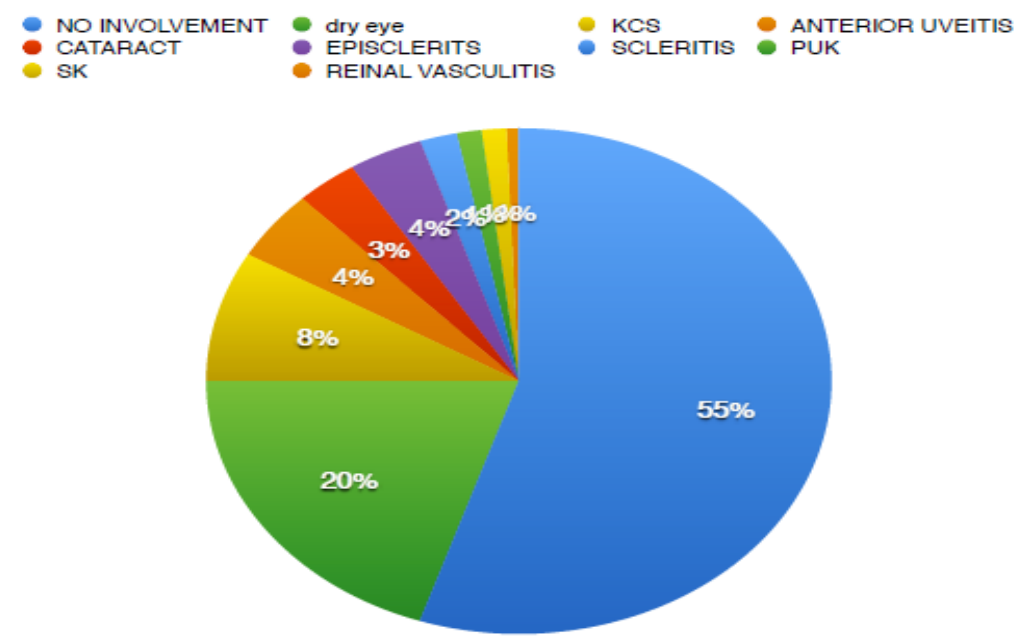

Fig 2: Different types of ocular involvement in patients with rheumatoid arthritis

Among 139 patients of rheumatoid arthritis included in our study, 53(38\%) patients had ocular signs and symptoms.

(Fig. 2) 31(22\%) patients had dry eye ,13 (9\%) had keratoconjunctivitis sicca(KCS), 7 (5\%) had anterior uveitis , 4 
(3\%) had episcleritis, 3(2\%) had scleritis, 2 (1.4\%) had peripheral ulcerative keratitis(PUK), $2(1.4 \%)$ had sclerosing keratitis, $5(3.5 \%)$ had cataract, and $1(0.7 \%)$ had rental vasculitis

Among 53 patients most commonly observed ocular problem in patients with Rheumatoid arthritis was dry eye in varying degree of severity. It was observed in $31(58.49 \%)$ patients, followed by uveitis in $7(13.2 \%)$, epi scleritis in $6(11.32 \%)$, cataract in $5(9.4 \%)$, scleritis in 3(5.6\%), Peripheral ulcerative keratitis(PUK) and sclerosing keratitisc (SK) in 2 each (3.77\%)and retinal vasculitis in $1(1.8 \%)$ patient. Table 1.

Table 1 Pattern of ocular involvement in patients of rheumatoid arthritis

\begin{tabular}{|l|r|r|}
\hline Disease Pattern & \multicolumn{2}{c|}{$\begin{array}{c}\text { percentage among 53 affected } \\
\text { cases }\end{array}$} \\
\hline Dry Eye & 31 & 58.4 \\
\hline Keratoconjunctivitis sicca & 13 & 14.34 \\
\hline Episcleritis & 4 & 11.3 \\
\hline scleritis & 3 & 5.6 \\
\hline Peripheral ulcerative Keratitis & 2 & 3.7 \\
\hline Sclerosing Keratitis & 2 & 3.7 \\
\hline Anterior Uvetis & 7 & 13.2 \\
\hline Cataract & 5 & 9.4 \\
\hline retinal vasculitis & 1 & 1.8 \\
\hline ischemic optic neuropathy & 0 & 0 \\
\hline
\end{tabular}

Out of 53 cases of RA with ocular involvement, 22 patients had multiple ocular involvement, 13 patients had two ocular complications while 9 had more than two different types of ocular complication.

Fig 3: Out of 53 patients of RA with ocular manifestations $38(71.6 \%)$ had bilateral and 15(28.4\%) had unilateral

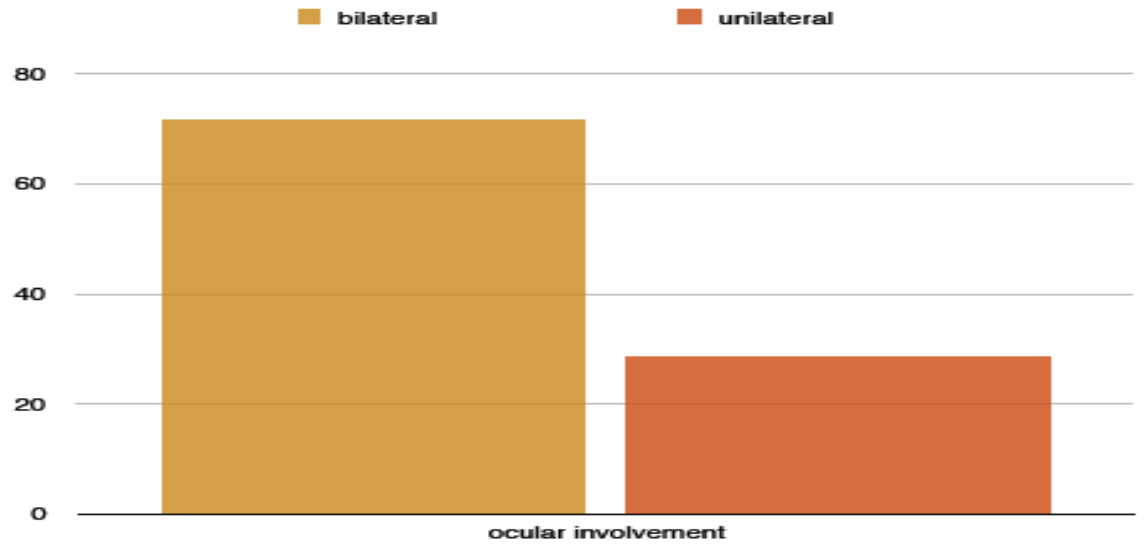

Table 2 : Demographic data and ocular manifestations in Rheumatic arthritis

\begin{tabular}{|c|c|c|c|c|c|c|c|c|c|}
\hline $\begin{array}{l}\text { ocular } \\
\text { manifes } \\
\text { tations }\end{array}$ & $\begin{array}{c}\text { patients } \\
\mathbf{n}(\%)\end{array}$ & $\begin{array}{l}\text { Mean } \\
\text { age } \\
\text { (Mean } \pm \\
\text { SD)year } \\
s\end{array}$ & $\begin{array}{l}\text { Female } \\
\text { s } \\
\text { n (\%) }\end{array}$ & $\begin{array}{c}\text { males } \\
(\%)\end{array}$ & $\begin{array}{l}\text { duratio } \\
\text { n of RA } \\
\text { (Mean } \pm \\
\text { SD)Year } \\
s\end{array}$ & $\begin{array}{l}\text { positive } \\
\text { ACCP } \\
n=117 \\
(84 \%)\end{array}$ & $\begin{array}{l}\text { positive } \\
\text { RF } \\
n=107 \\
(77 \%)\end{array}$ & $\begin{array}{l}\text { Both } \\
\text { ACCP } \\
\& \text { RF } \\
\text {-ve } \\
n=14 \\
(10 \%)\end{array}$ & $\begin{array}{l}\text { Both } \\
\text { RF \& } \\
\text { ACCP } \\
\text { positive } \\
\mathbf{n}=89 \\
(64 \%)\end{array}$ \\
\hline $\begin{array}{l}\text { ocular } \\
\text { signs/ } \\
\text { sympto } \\
\text { ms }\end{array}$ & $53(38.1)$ & $\begin{array}{l}41.65 \pm \\
25.54\end{array}$ & $43(81)$ & $10(19)$ & $\begin{array}{l}4.9 \pm \\
2.7\end{array}$ & $\begin{array}{l}40 \\
(35 \%)\end{array}$ & $\begin{array}{l}26 \\
(24 \%)\end{array}$ & $1(7 \%)$ & $\begin{array}{l}33 \\
(37 \%)\end{array}$ \\
\hline $\begin{array}{l}\text { no } \\
\text { ocular } \\
\text { sign / } \\
\text { sympto } \\
\text { ms }\end{array}$ & $\begin{array}{l}86(61.8 \\
7)\end{array}$ & $\begin{array}{l}35.53 \pm \\
19.60\end{array}$ & $67(78)$ & $19(22)$ & $\begin{array}{l}2.4 \pm \\
1.8\end{array}$ & $\begin{array}{l}77 \\
(65 \%)\end{array}$ & $\begin{array}{l}81 \\
(76 \%)\end{array}$ & $13(93 \%)$ & $\begin{array}{l}56 \\
(63 \%)\end{array}$ \\
\hline Total & 139 & & 110 & 29 & & 117 & 107 & 14 & 89 \\
\hline
\end{tabular}

RF: Rheumatoid Factor, ACCP Anti cyclic Citrullinated peptide antibodies. 
Out of 139 patients, 53(38\%) patients had ocular manifestations. Their mean age was $41.65 \pm 25.54$ and mean duration of RA was $4.9 \pm 2.7$ years . 117 patients had ACCP antibodies positive, 107 had RAF positive , 89 were positive for both ACCP and RAF and 14 were negative for both ACCP and RAF. In patients who were both ACCP and RAF positive 37\% (33) had ocular manifestations where as in patients with negative serology only one of them had ocular involvement. Amongst ACCP positive patients 35\%(40) and among RAF positive 24\%(26) had ocular manifestation.

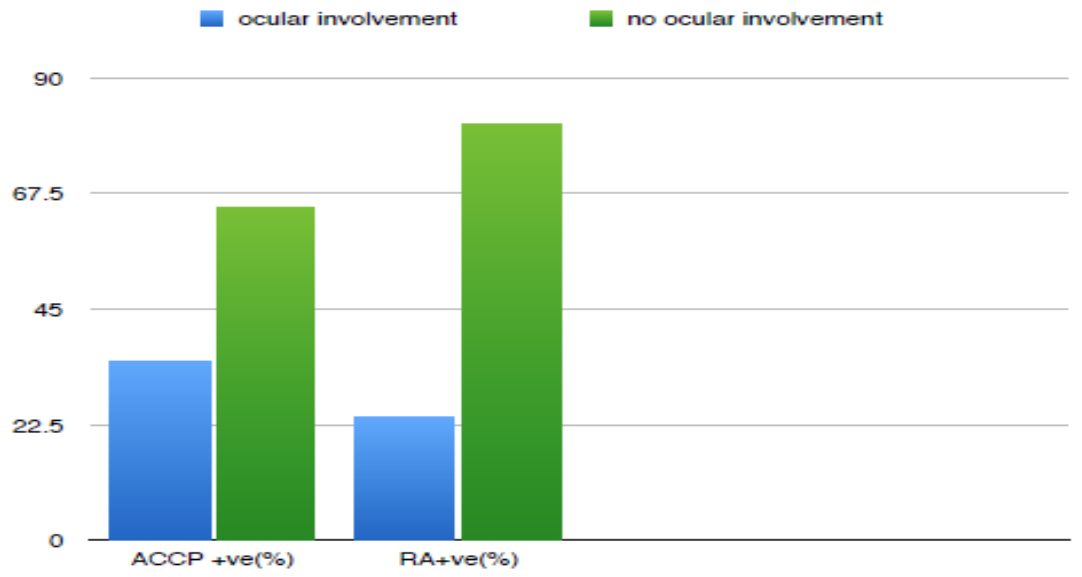

Fig 4 : Ocular involvement amongst sero positive RA patients.

Amongst 139 patients ,117(83\%) patients had ACCP antibody test positive and 107 had +ve RF. Though ocular findings were seen in more $(35 \%)$ in ACCP +ve patients than in RF +ve (24\%) but it was not statistically significant at $\mathrm{p}<.05 .(\mathrm{p}=.104877)$

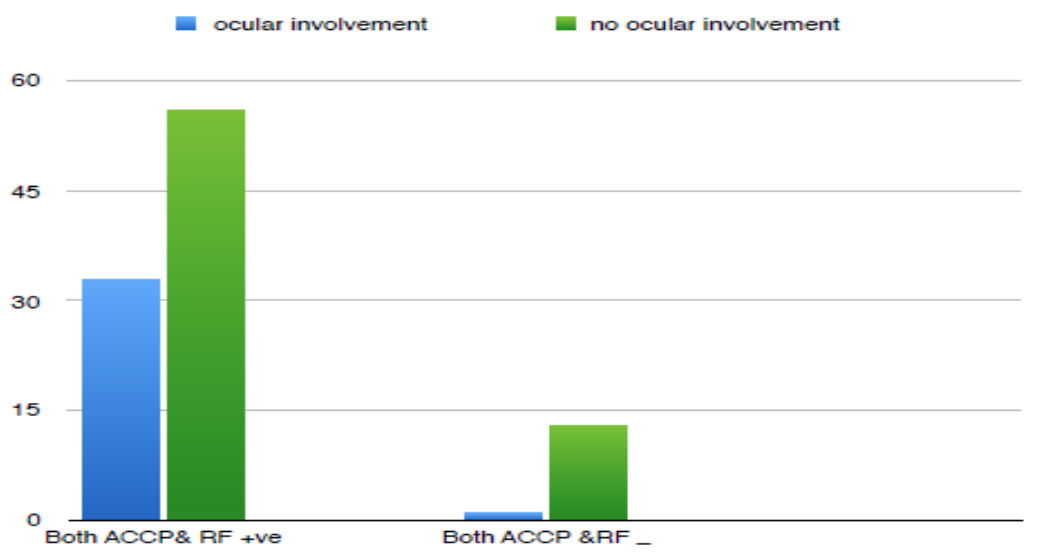

Fig 5 : Ocular involvement in sero +ve and sero -ve patients

The prevalence of ocular symptoms and signs was significantly higher in patients with both ACCP and $\mathrm{RAF}+\mathrm{ve}(37 \%)$ than who were sero negative. The $\mathrm{p}$ value was .005714 . The result was statistically significant at $\mathrm{p}<.05$

\section{Discussion}

Rheumatoid arthritis (RA) is one of the inflammatory arthropathy that not only cause irreparable damage to the joints but also may cause devastating systemic findings including ocular involvement. The inflammatory nature of RA with liberation of mediators of inflammation ,can result in tissue destruction which if involves eye may ultimately culminate in blindness. The present study was conducted on 139 diagnosed cases of rheumatoid arthritis where 53( 38\%) patients were found to have ocular manifestations. Similar results were reported by Reddy et al in 1977 (39\%), Bhadoria et al in 1989 (21\%) and Zlatanović G (27.2\%) in 2010[4,8,9] . Mean age of the patients with ocular involvement in the present study was $41.65 \pm 25.54$ years and of those without ocular involvement was $35.53 \pm 19.60$ years. Of the total 139 patients studied, $43(81 \%)$ females and 10 $(19 \%)$ males had ocular manifestations. Female predominance was seen in the studies conducted by Zlatanović $\mathrm{G}$, Markovitz E[4,12]. 
Dry eye syndrome(DES) is the most common ocular manifestation reported in patients of RA. It is thought to be caused by infiltration of the lacrimal gland by $\mathrm{T}$ and $\mathrm{B}$ lymphocytes ,leading to secondary atrophy of the gland and consequent decreased production of tears [10]. In our study 39 patients complained of foreign body sensation and redness of eyes and on examination 31(22.3\%) had dry eyes . $13(9.3 \%)$ of them had KCS while others had mild to moderate dry eye . Reddy et al. in 1977 reported dry eye in 29\%, Punjabi et al in 2006 in $27.3 \%$ and Ammapati Paul in 28\% cases of RA in 2015.[8,11,1] Tong L and Zlatanović G also reported DES as the dominant ocular manifestation.[2,4] Markovitz E in 2011 observed 85\% patients of RA suffering from dry eye.[12] Bhadoria et al found KCS in $17.7 \%$ cases[9].

Hamideh F et al observed KCS and anterior uveitis as the most common finding in RA . [6]Anterior uveitis was also reported by Reddy et al (4\%) in 1977and Ciurtin C et al in 2008[13]. In our study 7 (5\%) cases presented with anterior uveitis . McGavin et al studied 4,210 patients with RA and observed episcleritis in $0.17 \%$ and scleritis in $0.67 \%$ patients.[14] Reddy et al reported episcleritis in $1 \%$ patients and Bhadoria et al in $0.93 \%$ patients. [8,9] In the present study we found episcleritis in $3 \%$ and scleritis in $2 \%$ cases, a little higher than the previous studies but the similar results were also reported by Ammapati et al in 2015 (3\% episcleritis and $2 \%$ scleritis) and Zlatanović $\mathrm{G}$ in 2010(5\% episcleritis and 2\% scleritis) [1,4] Posterior sub capsular cataract has been reported in literature in theses patients. We found it in $5(3.5 \%)$ patients. All the five patients were females, above 50 years of age and on long term steroids for RA while three of them also had recurrent attacks of anterior uveitis. Ammapati et al in their study reported cataract in $1 \%$ cases where as Reddy et al in $9 \%$ cases.[1,8] Cojocaru et al reported nine cases of cataract and all as a complication clearly related to steroid therapy[15]. Hamideh F also observed sub capsular cataract and sub luxation of lens in their study. [6] .

Sight threatening complications PUK,SK were observed in $2(3.77 \%)$ patients each and retinal vasculitis in $1(1.8 \%)$ patient in the present study. Atchia et al in 2006 reported a RA patient with necrotising scleritis and P U K which was successfully treated with Infliximab [16] Lesley-Anne Goodisson et al reported a case of bilateral PUK following treatment with Rituximab for RA in 2010 [17].Tong L et al in 2014 reported that tissue damage in sight threatening complications like scleritis, PUK, SK in RA is auto immune mediated[2]. Ammapati et al found one case each of PUK and SK in their study on RA patients in 2015[1]. Squirrell et al in their case series concluded that RAassociated PUK often has a poor visual outcome and its appearance may herald the transformation of a patient's RA into the systemic vasculitic phase which if not managed aggressively with immunosuppression is associated with high morbidity and mortality. Retinal complications are comparatively rarer[18]. Reddy et al found 1 cases each of retinal hemorrhage and unilateral disc edema and Curtin $\mathrm{C}$ et al in 2008 found 3 patients who developed optic neuritis and retinal vasculitis in their retrospective descriptive study on 375 RA patients. Zlatanović G et al in 2010 also observed retinal vasculitis in $3(0.45 \%)$ patients[4,5] . In the present study we found retinal vasculitis only in one(1.8\%) patient.

Out of 53 patients, 38(71.6\%) had bilateral ocular involvement and 15(28.4\%) unilaterally affected had predominantly inflammatory ocular disease . Reddy et al also found bilateral involvement in $26(66 \%)$ patients. Pulido JS et al in a retrospective study at Mayo clinic concluded that patients who were both anti-CCP and RF positive tended to have more and worse ocular disease[19].In the present study, patients with positive serology had signific ntly higher prevalence of ocular manifestations $(\mathrm{p}<.05)$ More over all the patients with sight threatening complications were positive for ACCP antibodies and RA factor. Our observation is also supported by the study conducted by C Turesson in 2003 and Ammapati et al in 2015[20,1]. Thus their presence can help in early detection and management of the ocular manifestations and prevent permanent visual disability.

\section{Conclusions}

Patients of rheumatoid arthritis need to get routine ocular examination for the early diagnosis and timely management so as to prevent permanent irreparable loss of vision. The presence of anti CCP antibodies and RF provides effective clue to ophthalmologists for identifying patients at risk for vision threatening inflammatory ocular complications.

\section{Biblography}

[1]. Vignesh APP, Srinivasan R. Ocular manifestations of rheumatoid arthritis and their correlation with anti-cyclic citrullinated peptide antibodies. Clinical Ophthalmology (Auckland, NZ). 2015;9:393-397. doi:10.2147/ OPTH.S77210

[2]. Tong L, Thumboo J, Tan YK , Wong TY, Albani S ; The eye: a window of opportunity in rheumatoid arthritis? Nat Rev Rheumatol. 2014 Sep;10(9):552-60. doi: 10.1038/nrrheum.2014.85. Epub 2014 Jun 10.

[3]. Bobrzyk M, Łabuzek K, Orski M, Tarnawska D, Okopień Ocular symptoms in rheumatic diseases.Pol Merkur Lekarski. 2014 May;36(215):357-60.

[4]. Zlatanović G, Veselinović D, Cekić S, Zivković M, Dorđević-Jocić J, Zlatanović M. Ocular manifestation of rheumatoid arthritisdifferent forms and frequency. Bosn J Basic Med Sci. 2010 Nov; 10(4):323-7.

[5]. Ciurtin C, Cojocaru VM, Aramă S, Stoica V. Epidemiology of ocular involvement in autoimmune diseases.Rom J Intern Med. 2008;46(3):243-7.

[6]. Hamideh F, Prete PE. Ophthalmologic manifestations of rheumatic diseases. Semin Arthritis Rheum. 2001 Feb;30(4):217-41. 
[7]. Masi AT, Maldonado-Cocco JA, Kaplan SB, Feigenbaum SL, Chandler RW. Prospective study of the early course of rheumatoid arthritis in young adults: comparison of patients with and without rheumatoid factor positivity at entry and identification of variables correlating with outcome. Semin Arthritis Rheum. 1976;4:299-326.

[8]. Reddy SC, Gupta SD, Jain IS, Deodhar SD. Ocular manifestations of rheumatoid arthritis. Indian J Ophthalmol. 1977;25(3):20-26.

[9]. Bhadoria DP, Bhadoria P, Sundaram KR, Panda A, Malaviya AN. Ocular manifestations of rheumatoid arthritis. J Indian Med Assoc. 1989;87(6):134-135.

[10]. Almaliotis, D., Zakalka, M., Gerofotis, A., Chatzicharalampous, K., Efstathiou, M., Daniilidis, M. and Karampatakis, V. (2016) Ocular Manifestations in Rheumatoid Arthritis. Open Journal of Ophthalmology, 6, 170-175

[11]. Punjabi OS, Adyanthaya RS, Mhatre AD, Jehangir RP. Rheumatoid arthritis is a risk factor for dry eye in the Indian population. Ophthalmic Epidemiol. 2006;13(6):379-384

[12]. Markovitz E, Perry ZH, Tsumi E, Abu-Shakra M. Ocular involvement and its' manifestations in rheumatoid arthritis patients .Harefuah. 2011 Sep;150(9):713-8, 751.

[13]. Ciurtin C, Cojocaru VM, Aramă S, Stoica V. Epidemiology of ocular involvement in autoimmune diseases. Rom J Intern Med. 2008;46(3):243-7.

[14]. McGavin DD, Williamson J, Forrester JV, et al. Episcleritis and scleritis. A study of their clinical manifestations and association with rheumatoid arthritis. Br J Ophthalmol. 1976;60(3):192-226.

[15]. Cojocaru VM, Ciurtin C, Pop M, Tomi A, Grecu Ophthalmological involvement in rheumatic disease P Oftalmologia. 2006;50(2):56-61.

[16]. Atchia II, Kidd CE, Bell RW . Rheumatoid arthritis-associated necrotizing scleritis and peripheral ulcerative keratitis treated successfully with infliximab. J Clin Rheumatol. 2006 Dec;12(6):291-3.

[17]. Lesley-Anne Goodisson, John T. Bourne and Senthil Maharajan A case of bilateraLperipheral ulcerative keratitis following treatment with rituximab Rheumatology (2010) 49 (3): 609-610.

[18]. Squirrell DM, Winfield J, Amos RS. Peripheral ulcerative keratitis 'corneal melt' and rheumatoid arthritis: a case series. Rheumatology (Oxford). 1999 Dec;38(12):1245-8.

[19]. Pulido JS, Bakri SJ, Baratz KH et al Anti cyclic citrullinated Peptide , Rheumatoid factor and ocular symptoms typical of Rheumatoid Arthritis. Trans Am ophthal soc 2008;106:75-83

[20]. C Turesson, W M O'Fallon, C S Crowson, S E Gabriel, E L Matteson Extra-articular disease manifestations in rheumatoid arthritis: incidence trends and risk factors over 46 years Ann Rheum Dis 2003;62: 722-727 